\title{
Effect of cooling methods on dimensional accuracy and surface finish of a turned titanium part
}

\author{
M. N. Islam* J. M. Anggono, A. Pramanik, B. Boswell \\ Department of Mechanical Engineering, Curtin University, Bentley, WA 6102, \\ Australia
}

\begin{abstract}
s
In metal cutting, the choice of cooling method influences the deformation mechanism, which is related to the dimensional accuracy and surface finish of the parts. The deformation mechanism of titanium alloys under machining conditions is known to be very different from that of commonly used industrial materials. Therefore, the effect of cooling methods on dimensional accuracy and surface finish in machining titanium is of particular interest. This paper investigates experimentally and analytically the influence of cooling method and cutting parameters on two major dimensional accuracy characteristics of a turned titanium part-diameter error and circularity, and surface finish. Data were analyzed via three methods: traditional analysis, Pareto ANOVA, and Taguchi method. The findings indicate that the cooling method has significant effect on circularity error (contribution ratio $76.75 \%$ ), moderate effect on diameter error (contribution ratio $25.00 \%$ ) and negligible effect on surface finish (contribution ratio $0.16 \%)$.
\end{abstract}

Keywords: Dry turning, flood turning, cryogenic cooling turning, titanium alloy, Pareto ANOVA, Taguchi method

*Corresponding author, Phone: +618 9266 3777, Fax: +618 9266 2681, Email: M.N.Islam@curtin.edu.au 


\section{Introduction}

Titanium alloys are the most important and widely used metallic alloys in the aerospace industries [1]. However, such materials are difficult to machine [2]. The deformation process of titanium alloys is very different to that of commonly used materials, such as aluminum and steel. Under machining conditions (high temperature, strain rate, and strain), titanium alloys undergo different types of deformation process according to the machining parameters. Stress, temperature, and vibration within the machining zone are the three main factors associated with damage to cutting tools, dimensional error and rough surface [3]. Tool wear, surface integrity, dimensional error, and productivity are correlated, and depend on cutting parameters such as cutting speed, feed rate and depthof-cut, type of coolant and cutting tool materials [4]. Among these, coolant, cutting speed, and feed rate play significant roles in high-speed machining. Coolant improves machinability by reducing the machining temperature and inducing lubrication effect in tool-chip and tool-machined surface interfaces. The improvement of high-speed machinability of titanium alloys depends to a large extent on the effectiveness of the cooling/lubrication. Improved machinability generally refers to longer tool life, better surface finish, and greater dimensional accuracy.

Several technologies, such as cryogenic cooling, solid coolants/lubricants, minimum quantity lubrication (MQL)/near-dry machining (NDM), high-pressure coolants (HPC), internal tool cooling and compressed air/gases have been developed in recent years to control temperature in the cutting zone and increase the overall effectiveness of the cooling and lubrication process [5]. Hong et al. [6] designed micro-nozzles and injected liquid nitrogen to the cutting edge and the chip-tool interface at the point of highest temperature in order to improve tool life. Wang et al. [7] reported a three-fold 
improvement in tool life when using liquid nitrogen cooling in turning Ti-6Al-4V alloy. Kovacevic et al. [8] investigated the effect of high-pressure water-jet cooling to improve surface quality and tool life in the milling of titanium alloy. In all cooling methods, the coolant needs to reach the cutting zone for effective improvement in machinability.

So far, the main focus of studies on titanium machining is to understand the machining mechanism and reduce tool wear. Segmentation (normally known as saw-tooth chip) is a characteristic shape of the chip when machining titanium alloys [9]. This chip is distinctly different from the 'continuous' or 'uniform-shear' chip formed during the machining of titanium alloys under conventional/low-speed cutting conditions [10]. The mechanism of saw-tooth chip formation in machining titanium alloys is due to the occurrence of thermo-plastic instability within the primary shear zone [11]. This is followed by the growth of cracks [12] and adiabatic shear-band formation associated with the predominance of strain-hardening over thermal softening, and the difficulty of dislocation motion through the microstructure [10]. The temperature can be very high and localized in some areas of a workpiece, due to low thermal conductivity of Ti-6Al$4 \mathrm{~V}$ alloy. The transition in crystalline structure is thought to result primarily from the high pressure and temperature that accompany plastic deformation [10]. The onset of shear instability in chips is associated with cutting conditions and the material properties of the workpiece [13].

Different types of cutting tools have been tested for machining different types of titanium alloys [14]. The main causes of tool wear for different cutting tools are: coating delamination (coated tool), adhesion, attrition, diffusion, plastic deformation, and cracks [15]. The chemical reaction and difference in the thermal expansion coefficient between the coating matrix and the substrate are two possible reasons for coating delamination. 
Adhesion of workpiece material to the cutting tool is very common during machining titanium [16]. Attrition wear is observed on the rake face as well as flank face. Evidence of diffusion of cobalt and tungsten atoms into the work material was found when machining with coated/uncoated carbide tools at relatively high cutting speed [17]. The extreme temperature, pressure and the intimate contact at the tool-chip interface promote the diffusion of tool material to the workpiece [18]. Ti, Al, and V within Ti6Al-4V alloy are seen to diffuse into WC (Co binder) tools during machining at higher cutting temperature. Under similar conditions, W and Co within the WC (Co binder) tool also diffuse into Ti-6Al-4V alloy [19]. These processes change the composition and affect the performance of the cutting tool [15]. This diffusion occurs due to the higher cutting temperature and smaller tool-chip interface at high cutting speeds, as mention earlier. Generally, several tool wear mechanisms take place simultaneously and affect one another, which deteriorate and weaken the cutting tool and promote the propagation of existing cracks [20].

The previous literature has paid notable attention to the dimensional accuracy and surface finish of turned parts in materials other than titanium alloy. A typical approach has been to study the effects of major cutting parameters on dimensional accuracy parameters such as diameter error, and circularity and surface finish parameters such as arithmetic average (Ra) and peak-to-valley height (Rt), for various materials such as free-machining steel [21], aluminum-copper alloy [22], chromium alloy tool steel SKD11 [23], maraging steel [24], composite materials [25], chrome molybdenum steel SCM 400 [26], mild steel 1030 [27], and alloy steel 4340 [28].

The above discussion indicates that significant attention has been given to understanding machining mechanisms of titanium alloys and thereby enhancing tool life 
[29]. Significant attention has been given to improving productivity when machining titanium with and without coolant. Many previous studies compared machinability characteristics, such as cutting force, cutting power, chip formation, and tool wear for different machining conditions. However, although machinability and quality characteristics are equally important for improved productivity, to the best of our knowledge, there are no previous investigations of how dimensional accuracy and surface roughness are affected by different cooling methods, cutting speed, and feed rate during machining of titanium alloy when tool wear is negligible. The unique deformation mechanism of titanium alloy is largely dependent on machining temperature. Thus, the diameter error, circularity, and surface roughness depend on the cooling methods, cutting speed and feed rate even when cutting tool wear is negligible. To address the above mentioned gap in the literature on titanium machining, this study aims to quantify and optimize the main and interaction effects of three input parameters - cooling method, cutting speed and feed rate — on the dimensional accuracy and surface finish of a turned titanium part.

\section{Scope}

Dimensional accuracy shows the degree of agreement between the measured dimension and its desired magnitude. According to current dimensioning and tolerancing standards [30], the dimensional accuracy of parts is evaluated through size tolerance and geometric tolerance, including form, orientation, and location tolerance. For turned component parts, the two most important dimensional accuracy characteristics are diameter error and circularity. Diameter error is especially important for component parts involved in a cylindrical fit, as the diameter error directly influences the clearance conditions of the fit. Circularity is important for rotating component parts, where 
excessive circularity values may cause unacceptable vibration and heat. These two dimensional accuracy characteristics are selected for the present study.

Diameter error represents variation in size (size tolerance), which is defined as the difference between the measured diameter and the designed diameter; therefore, a positive error represents undercutting of a cylindrical workpiece.

Circularity represents variation in form (geometric tolerance), which is defined by two concentric circular boundaries, within which each circular element of the surface must lie [30].

Surface roughness is a parameter widely used for representing the topography of a surface in short wavelengths. It comprises surface irregularities with small spacing and is of great importance to wear, corrosion, fatigue, noise, load-carrying capacity, heat transfer, and many other performance parameters. Surface roughness can be expressed through a number of parameters, such as the arithmetic average, root-mean-square roughness, peak-to-valley height, and ten-point height. The arithmetic average is the most commonly used roughness parameter because of its simplicity. In this study, arithmetic average is adopted to represent surface roughness, which can be calculated through Equation 1 [31]:

$$
R_{a}=\frac{1}{L} \int_{0}^{L}|Y(x) d x|
$$

where $R_{a}$ is the arithmetic average roughness, $Y$ is the vertical deviation from the nominal surface, and $L$ is the specified distance over which the surface roughness is measured. 
The results were analyzed via three techniques - traditional analysis, Pareto analysis of variation (ANOVA), and Taguchi's signal-to-noise $(\mathrm{S} / \mathrm{N})$ ratio analysis. Traditional analysis uses the mean values of the responses, a method that is primarily used for representing relationships between input and output variables. Nevertheless, it does not provide the complete picture because it does not typically include data on the variation of the responses.

Pareto ANOVA is an excellent tool for determining the contribution of each input parameter and their interactions with the output parameters (dimensional accuracy and surface finish characteristics). It is a simplified ANOVA analysis method based on the Pareto principle, also known as the $80-20$ rule, which states that roughly $80 \%$ of the effects come from $20 \%$ of the causes in many cases. It is a quick and easy method for analyzing results of a parameter design. It does not require an ANOVA table and does not use $F$-tests. Consequently, the Pareto principle does not require detailed knowledge about the ANOVA method. Further details on Pareto ANOVA are available in Park $[32]$.

The Taguchi method is another popular tool for parameter design. It applies the S/N ratio as a quantitative analysis tool for optimizing the outcome of a manufacturing process. The formula for calculating the $\mathrm{S} / \mathrm{N}$ ratio depends on the type of quality characteristics investigated. Equation 2 calculates the $\mathrm{S} / \mathrm{N}$ ratio of a quality characteristic in which the adage "the smaller the better" holds true [33]. All three quality characteristics considered in this study are of this category.

$$
S / N=-10 \log \frac{1}{n}\left(\sum_{i=1}^{n} y_{i}^{2}\right),
$$

where $n$ is the number of observations and $y$ is the observed data. 
There is a wide range of cooling methods available for turning operations. The present study examined three methods: dry (no coolant), flood (water-soluble coolant), and cryogenic. A titanium alloy (Ti-6Al-4V) was used as the work material. Some important properties and chemical compositions of the work material are listed in Tables 1 and 2, respectively.

Table 1 Properties of grade-5 titanium alloy (wt.\%) [34]

\begin{tabular}{ccccc}
\hline $\begin{array}{c}\text { Density } \\
(\mathbf{g} / \mathbf{c c})\end{array}$ & $\begin{array}{c}\text { Hardness } \\
(\mathbf{B H})\end{array}$ & $\begin{array}{c}\text { Shear } \\
\text { Modulus } \\
(\mathbf{G P a})\end{array}$ & $\begin{array}{c}\text { Modulus of } \\
\text { Elasticity } \\
(\mathbf{G P a})\end{array}$ & $\begin{array}{c}\text { Thermal } \\
\text { Conductivity } \\
(\mathbf{W} / \mathbf{m}-\mathbf{K})\end{array}$ \\
\hline 4.43 & 334 & 44 & 113.8 & 6.7 \\
\hline
\end{tabular}

Table 2 Chemical composition of grade-5 titanium alloy (wt.\%) [34]

\begin{tabular}{lr}
\hline Aluminium, Al & $5.50-6.75$ \\
Carbon, C & $<=0.0800$ \\
Hydrogen, H & $<=0.0150$ \\
Iron, Fe & $<=0.400$ \\
Nitrogen, N & $<=0.0300$ \\
Other, each & $<=0.0500$ \\
Other, total & $<=0.300$ \\
Oxygen, O & $<=0.200$ \\
Titanium, Ti & $87.725-91.0$ \\
Vanadium, V & $3.50-4.50$ \\
\hline
\end{tabular}

\section{Experimental work}

The experiments were planned using Taguchi's orthogonal array and a three-level threeparameter $L_{27}\left(3^{13}\right)$ orthogonal array was selected. A copy of the $L_{27}\left(3^{13}\right)$ array is available in [35]. A total of 27 machinable segments were produced (nine segments in each workpiece) for each of the three cooling methods: dry (no coolant), flood (water 
soluble coolant) and cryogenic (liquid nitrogen). For each cooling method, a workpiece was divided via grooving operations of approximately $2.5 \mathrm{~mm}$ in depth, into 9 sections each of $20 \mathrm{~mm}$ length. Nominal diameter of $45 \mathrm{~mm}$ and total length of $310 \mathrm{~mm}$ were selected to maintain the length-to-diameter ratio well below 8:1 in order to avoid bending and oscillations during the machining process. The experiment was carried out on a conventional Harrison lathe with 330-mm swing under different cutting speeds and feed rates, as given in Table 3.

Table 3 Control parameters and their levels.

\begin{tabular}{lccccc}
\hline & & \multicolumn{3}{c}{ Levels } \\
\cline { 4 - 6 } Control & \multirow{2}{*}{ Units } & Symbols & Level 0 & Level 1 & Level 2 \\
\hline Parameters & & A & Dry & Flood & Cryogenic \\
Cooling type & - & & 43 & 67 & 100 \\
Cutting speed & $\mathrm{m} / \mathrm{min}$ & $\mathrm{B}$ & 0.11 & 0.22 & 0.33 \\
\hline
\end{tabular}

A three-jaw chuck supported at dead-center was used to hold the workpiece. Cutting tools were cobalt-coated positive diamond-shape inserts (DCMT-11T308-MM-2025; Sandvik). The inserts were mounted on Sandvik's QS-SDJCR-1616-E11-HP tool holder, due to compatibility with the DCMT insert as well as the attachment to the dynamometer. A new cutting tip was used for machining each part to avoid any effect of tool wear.

For flood turning, a Rocol Ultracut Longlife soluble oil cutting fluid was applied at a flow rate of 0.04 1/sec. For dry turning, no coolant was used. Liquid nitrogen was applied for cryogenic cooling. The system for delivering liquid nitrogen comprised a 
self-pressurized liquid nitrogen dewar (MVE Lab 30) along with a custom-built steel pipe nozzle (6 $\mathrm{mm}$ internal diameter).

Precision measurements were taken using a Discovery Model D-8 coordinate measuring machine (CMM), manufactured by Sheffield, UK. The probes were spherical with a star configuration (Renishaw Electrical Ltd., UK). The diameters of the test parts were determined using the standard built-in CMM software. Eight points were recorded for each measurement of diameter, and each measurement was repeated three times. The circularity data were also obtained from the CMM. The arithmetic average $\left(\mathrm{R}_{\mathrm{a}}\right)$ surface roughness parameter for each turned surface was determined by a surface-measuring instrument (Surftest SJ-201P, Mitutoyo, Japan).

\section{Results and Analysis}

A large data set was obtained and subsequently analyzed. Due to space constraints, only a few data are presented, although all of the relationships were considered at different stages. Due to the multi-variability of data, it is possible to present them in a number of ways. The adopted format was carefully chosen to maximize the clarity of the presentation. Experimental results for diameter error, circularity, surface roughness, and their corresponding $\mathrm{S} / \mathrm{N}$ ratios are summarized in Table 4.

\subsection{Diameter Error}

Pareto ANOVA analysis (Table 5) shows that parameter B (cutting speed) has the most significant effect on diameter error, with a contribution ratio of $P=27.10 \%$, followed by A (cooling type), $P=25.00 \%$, and C (feed rate) $P=8.90 \%$ with the least influence. The interaction between $(\mathrm{B} \times \mathrm{C})$ parameters (cutting speed and feed rate) also plays a 
role in the cutting process $(P=11.63 \%)$. It is worth pointing out that the total contribution of the main effects is about $61 \%$, compared to the total $39 \%$ contribution of the interaction effects, thus making it difficult to optimize the diameter error by selection of input parameters.

The results obtained from the Pareto ANOVA analysis in Table 5 are verified by the response table and the response graph for the mean $\mathrm{S} / \mathrm{N}$ ratio, as shown in Table 6 and Figure 1, respectively. The results show that parameter B (cutting speed) has the most significant effect on diameter error, which supports the results obtained from the Pareto ANOVA analysis in Table 5. 
Table 4 Experimental results for diameter cutting force, diameter error, surface roughness, circularity, and corresponding $\mathrm{S} / \mathrm{N}$ ratios.

\begin{tabular}{|c|c|c|c|c|c|c|}
\hline \multirow[b]{2}{*}{$\begin{array}{c}\text { Expt. } \\
\text { number }\end{array}$} & \multicolumn{3}{|c|}{ Measured Parameters } & \multicolumn{3}{|c|}{ Calculated S/N ratio } \\
\hline & $\begin{array}{c}\text { Diameter } \\
\text { error } \\
(\mathrm{mm})\end{array}$ & $\begin{array}{l}\text { Circularity } \\
(\mu \mathrm{m})\end{array}$ & $\begin{array}{c}\text { Surface } \\
\text { roughness } \\
(\mu \mathrm{m})\end{array}$ & $\begin{array}{c}\mathrm{S} / \mathrm{N} \text { ratio } \\
\text { for diameter } \\
\text { error }\end{array}$ & $\begin{array}{l}\mathrm{S} / \mathrm{N} \text { ratio } \\
\text { for } \\
\text { circularity }\end{array}$ & $\begin{array}{l}\text { S/N ratio for } \\
\text { surface } \\
\text { roughness }\end{array}$ \\
\hline 1 & 0.30 & 7.07 & 1.25 & 10.53 & -17.16 & -1.95 \\
\hline 2 & 0.30 & 6.26 & 2.14 & 10.58 & -15.93 & -6.61 \\
\hline 3 & 0.29 & 5.26 & 4.04 & 10.82 & -15.18 & -12.13 \\
\hline 4 & 0.19 & 6.16 & 0.91 & 14.56 & -15.97 & 0.81 \\
\hline 5 & 0.19 & 5.12 & 1.97 & 14.33 & -14.42 & -5.87 \\
\hline 6 & 0.16 & 6.91 & 4.19 & 16.04 & -17.44 & -12.45 \\
\hline 7 & 0.13 & 5.47 & 0.97 & 17.46 & -15.02 & 0.24 \\
\hline 8 & 0.08 & 7.31 & 2.00 & 21.77 & -17.47 & -6.04 \\
\hline 9 & 0.18 & 9.03 & 4.36 & 14.00 & -19.26 & -12.78 \\
\hline 10 & 0.22 & 6.41 & 0.93 & 13.30 & -16.31 & 0.66 \\
\hline 11 & 0.23 & 6.83 & 1.94 & 12.87 & -16.78 & -5.78 \\
\hline 12 & 0.14 & 9.32 & 4.39 & 16.85 & -19.72 & -12.84 \\
\hline 13 & 0.19 & 7.25 & 1.15 & 14.39 & -17.53 & -1.25 \\
\hline 14 & 0.14 & 8.00 & 2.09 & 16.97 & -18.10 & -6.40 \\
\hline 15 & 0.11 & 8.75 & 4.18 & 18.97 & -18.89 & -12.42 \\
\hline 16 & 0.11 & 7.36 & 0.84 & 19.51 & -17.50 & 1.49 \\
\hline 17 & 0.08 & 5.78 & 1.92 & 21.68 & -15.33 & -5.67 \\
\hline 18 & 0.18 & 11.22 & 4.22 & 14.66 & -22.28 & -12.50 \\
\hline 19 & 0.17 & 19.25 & 0.87 & 15.45 & -26.07 & 1.21 \\
\hline 20 & 0.12 & 12.70 & 2.42 & 18.63 & -22.10 & -7.68 \\
\hline 21 & 0.14 & 11.31 & 4.70 & 17.06 & -21.70 & -13.45 \\
\hline 22 & 0.12 & 9.49 & 0.84 & 18.60 & -19.66 & 1.46 \\
\hline 23 & 0.08 & 11.66 & 2.06 & 21.48 & -21.60 & -6.29 \\
\hline 24 & 0.13 & 13.43 & 4.41 & 17.72 & -23.44 & -12.88 \\
\hline 25 & 0.02 & 14.05 & 0.99 & 31.05 & -23.57 & 0.12 \\
\hline 26 & 0.01 & 11.47 & 3.47 & 42.70 & -21.47 & -10.80 \\
\hline 27 & 0.19 & 10.51 & 3.60 & 14.34 & -20.57 & -11.13 \\
\hline
\end{tabular}


Table 5 Pareto ANOVA analysis for diameter error

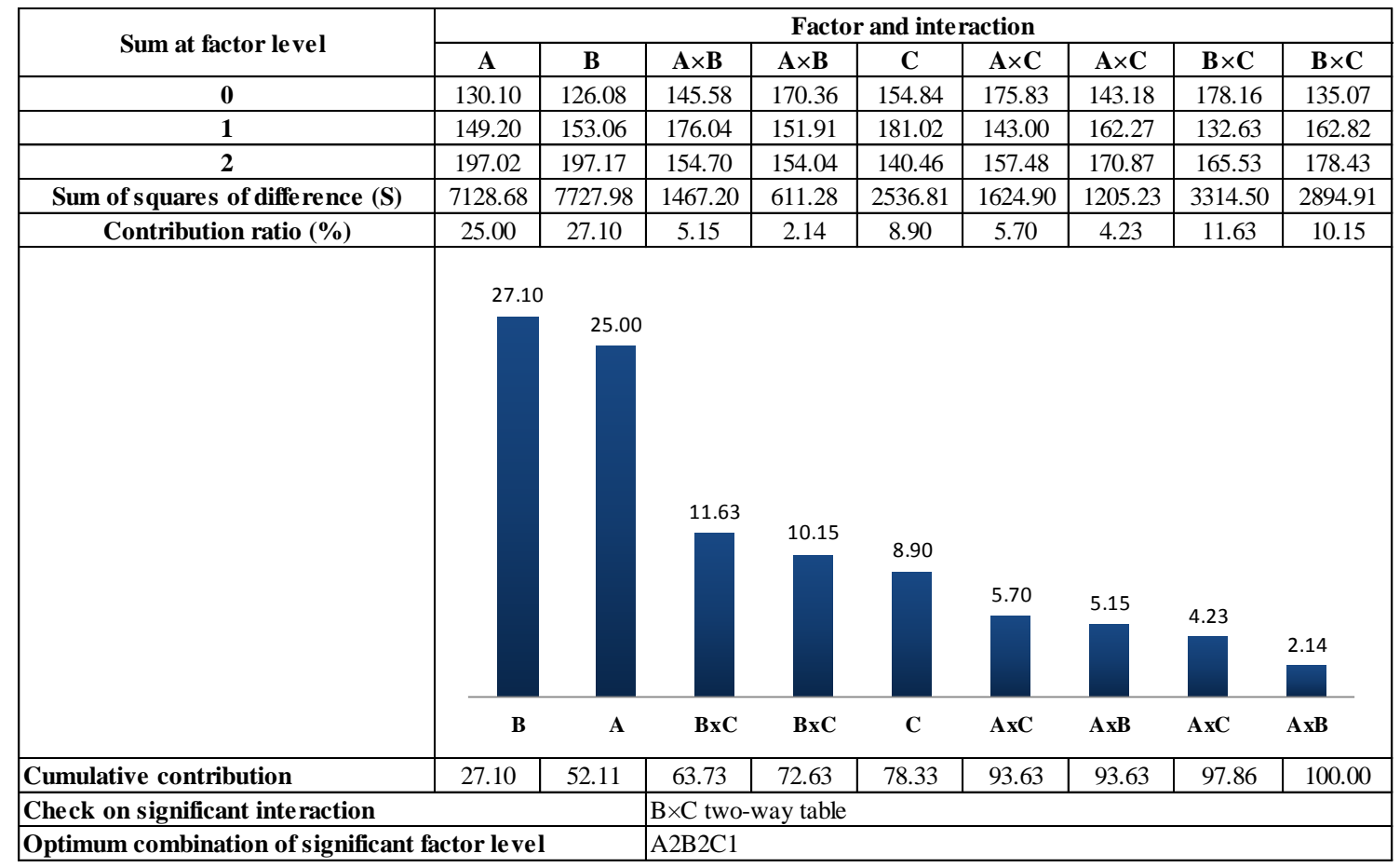

Table 6 Response table for mean $\mathrm{S} / \mathrm{N}$ ratio for diameter error, and significant interaction

\begin{tabular}{lcrrrr}
\hline & & \multicolumn{4}{c}{ Mean S/N Ratio } \\
\cline { 3 - 6 } Input Parameters & Symbol & Level 0 & Level 1 & Level 2 & Max - Min \\
\hline Cooling Type & $\mathrm{A}$ & 14.46 & 16.58 & 21.89 & 7.43 \\
Cutting Speed & $\mathrm{B}$ & 14.01 & 17.01 & 21.91 & 7.90 \\
Feed Rate & $\mathrm{C}$ & 17.20 & 20.11 & 15.61 & 4.51 \\
Interaction B $\times \mathrm{C}$ & $\mathrm{B} \times \mathrm{C}$ & 19.80 & 14.74 & 18.39 & 5.06 \\
\hline
\end{tabular}

In selecting the optimum combination of parameters, both the Pareto ANOVA analysis (Table 5) and the response for the mean S/N ratio (Table 6 and Figure 1) confirm that the high cooling type, $\mathrm{A}_{2}$ (cryogenic cooling) provides optimum cooling in achieving the lowest diameter error. A two-way table of $\mathrm{B} \times \mathrm{C}$ interactions showed that $\mathrm{B}_{2} \mathrm{C}_{1}$ achieved the lowest diameter error; i.e., high level of cooling (cryogenic), high cutting 
speed $(100 \mathrm{~m} / \mathrm{min})$ and medium feed rate $(0.22 \mathrm{~mm} / \mathrm{rev})$. The two-way table is not included in this paper due to space constraints.

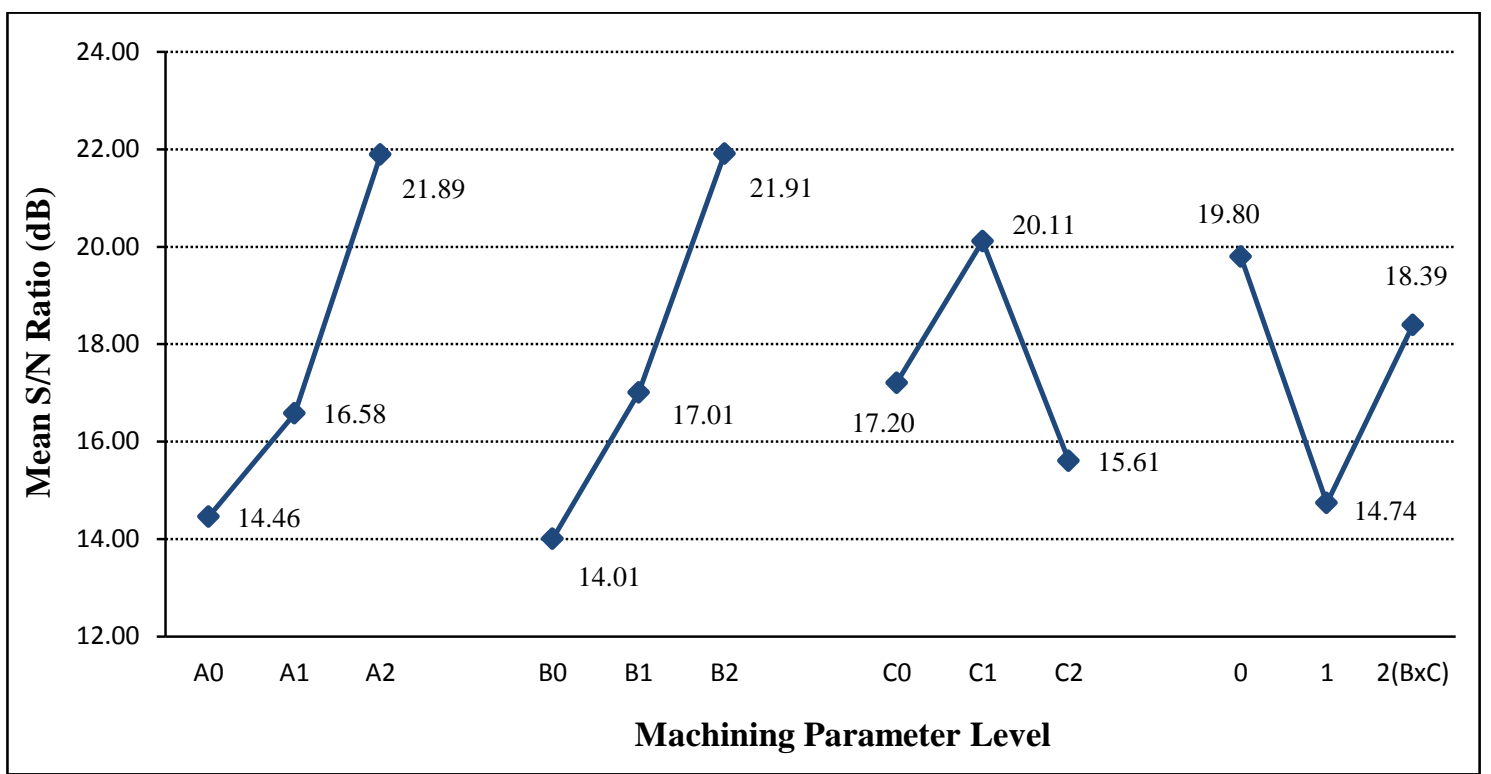

Figure 1 Response graph for mean $\mathrm{S} / \mathrm{N}$ ratio for diameter error

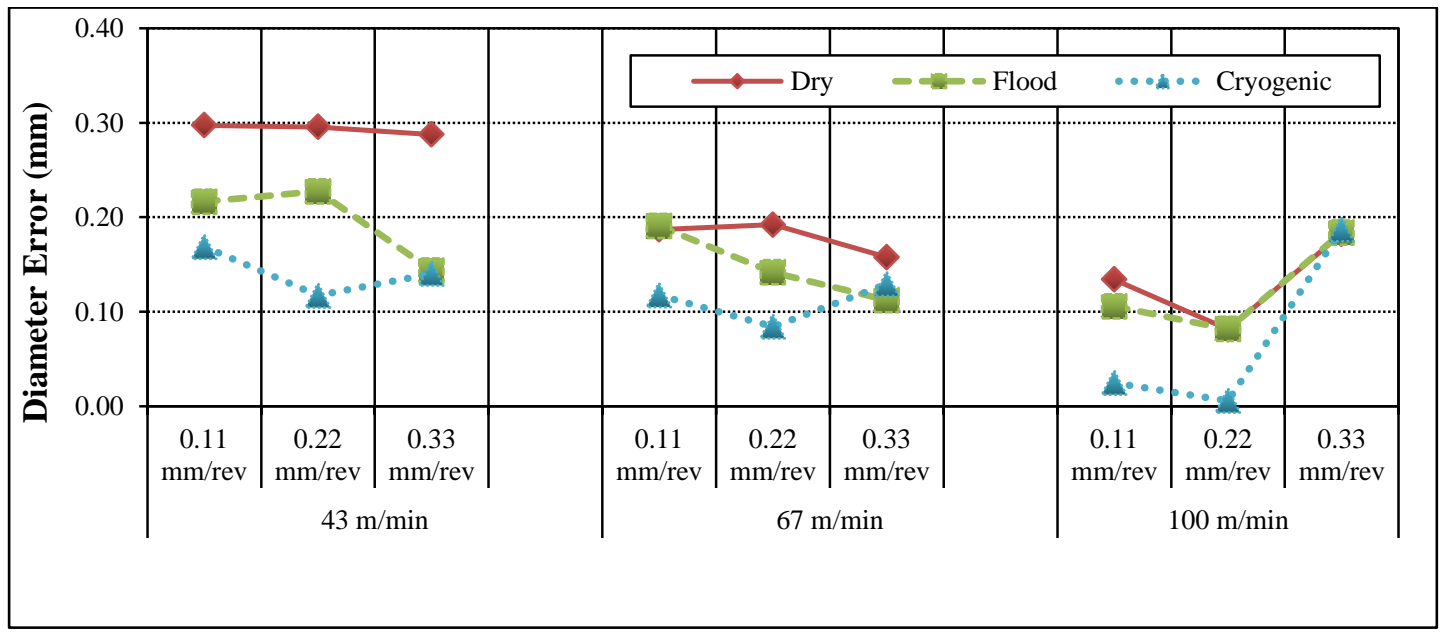

Figure 2 Variation of diameter error under three input parameters 
Further analyses using the traditional methods were conducted as an additional verification of the Pareto ANOVA (Table 5) and the Taguchi S/N response graph and table (Table 6 and Figure 1). As illustrated in

Figure 2 and 3, the minimum diameter error is achieved at high level of cooling (cryogenic), high cutting speed $(100 \mathrm{~m} / \mathrm{min})$ and medium feed rate $(0.22 \mathrm{~mm} / \mathrm{rev})$. These results confirm those obtained from the Pareto ANOVA and Taguchi S/N response.

Furthermore, Figure 2 shows that for dry- and flood cooling under low- and medium cutting speed, the diameter error decreases as the feed rate increases. On the other hand, cryogenic cooling shows a different trend: as the feed rate increases from low to medium level, the diameter error decreases, but when the feed rate increases further from medium to high level, the diameter error increases.

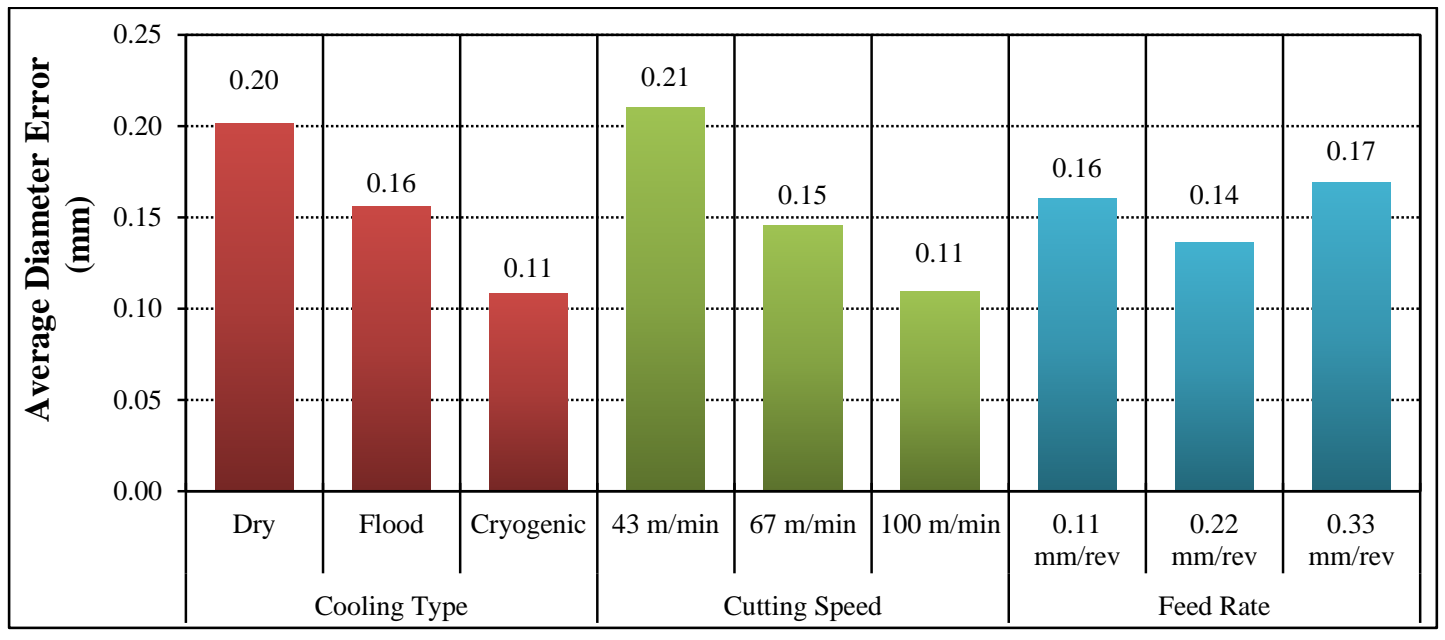

Figure 3 Average variation of diameter error under three input parameters 


\subsection{Circularity}

The Pareto ANOVA analysis on the effect of feed rate, cutting speed, and cooling is tabulated in Table 7. It shows that parameter A (cooling type) has the most significant effect on circularity, with a contribution of $P=76.75 \%$, followed by $\mathrm{C}$ (feed rate; $P=$ $6.29 \%$ ) and $\mathrm{B}$ (cutting speed; $P=0.83 \%$ ). The interaction between parameters $\mathrm{A} \times \mathrm{C}$ (cooling type and feed rate) also plays a role in the cutting process, with $P=5.37 \%$. The total contribution of the main effects is about $84 \%$, compared to the total $16 \%$ contribution of the interaction effects, thus making it relatively easier to optimize the circularity error by selection of input parameters.

The results obtained from the Pareto ANOVA analysis in Table 7 are verified by the response table (Table 8) and response graph (Figure 4) for the mean $\mathrm{S} / \mathrm{N}$ ratio. The results show that parameter A (cooling type) has the most significant effect on circularity, which confirms the results obtained from the Pareto ANOVA analysis in Table 7.

Both the Pareto ANOVA analysis (Table 7) and the response for the mean S/N ratio (Table 8 and Figure 4) confirm that the medium cutting speed, B1 (value at $67 \mathrm{~m} / \mathrm{min}$ ) achieves the best circularity. A two-way table was used to analyze the optimum $\mathrm{A} \times \mathrm{C}$ interaction, showing that $\mathrm{A} 0 \mathrm{C} 1$ achieved the best circularity. Thus, the optimum combination to achieve the best circularity is A0B1C1; i.e., low cooling type (dry), medium cutting speed $(67 \mathrm{~m} / \mathrm{min})$ and medium feed rate $(0.22 \mathrm{~mm} / \mathrm{rev})$. 
Table 7 Pareto ANOVA analysis for circularity

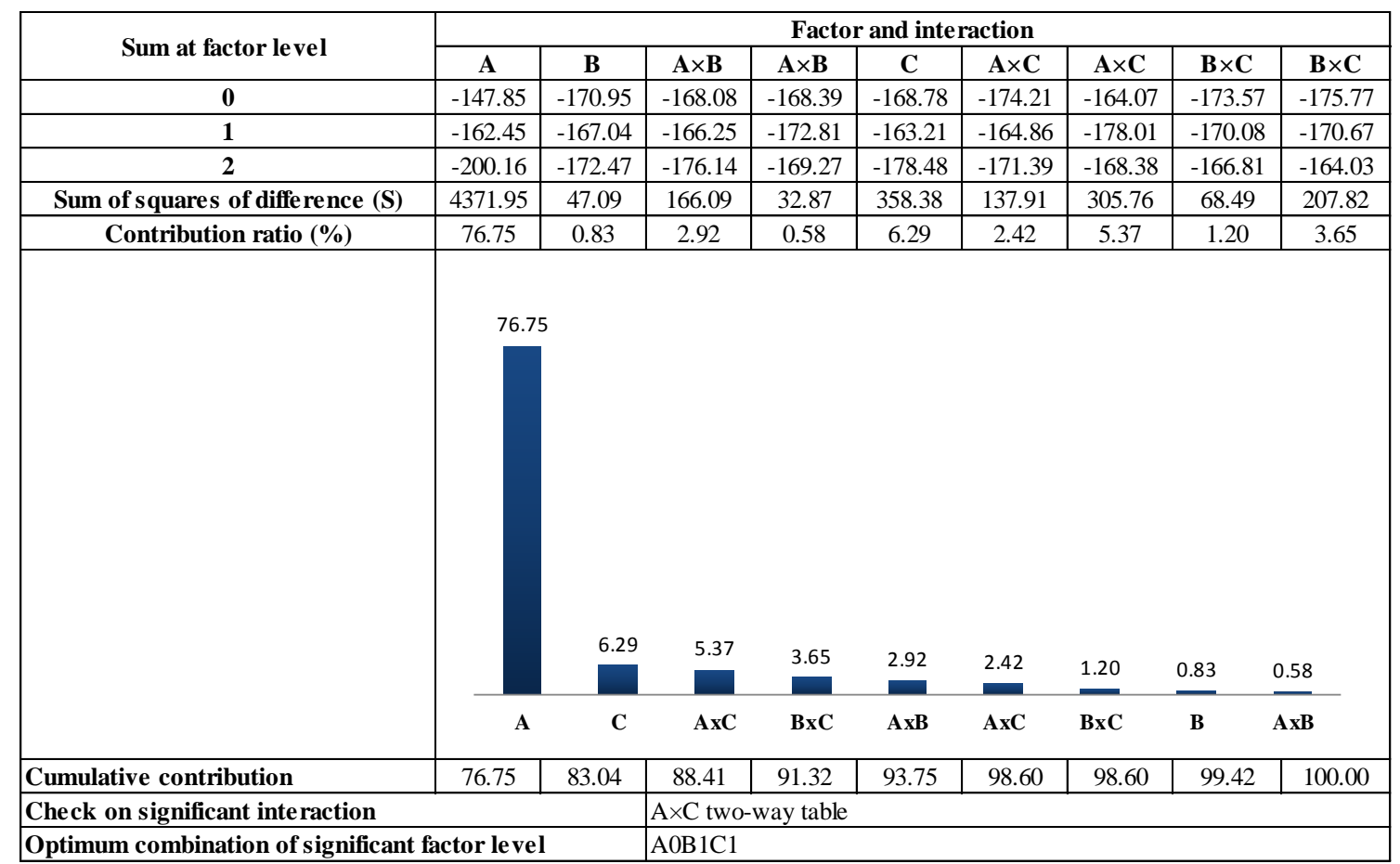

Table 8 Response table for mean $\mathrm{S} / \mathrm{N}$ ratio for circularity, and significant interaction

\begin{tabular}{lcrrrr}
\hline & & \multicolumn{4}{c}{ Mean S/N Ratio } \\
\cline { 3 - 6 } Input Parameters & Symbol & Level 0 & Level 1 & Level 2 & Max - Min \\
\hline Cooling Type & $\mathrm{A}$ & 14.46 & 16.58 & 21.89 & 7.43 \\
Cutting Speed & $\mathrm{B}$ & 14.01 & 17.01 & 21.91 & 7.90 \\
Feed Rate & $\mathrm{C}$ & 17.20 & 20.11 & 15.61 & 4.51 \\
Interaction A $\times \mathrm{C}$ & $\mathrm{A} \times \mathrm{C}$ & 19.80 & 14.74 & 18.39 & 5.06 \\
\hline
\end{tabular}

Further analyses using the traditional methods were conducted as an additional verification of the Pareto ANOVA (Table 7) and the Taguchi S/N response (Table 8 and Figure 4). As illustrated in Figures 5 and 6, the best circularity is achieved at low cooling level (dry), medium cutting speed $(67 \mathrm{~m} / \mathrm{min})$ and medium feed rate $(0.22$ $\mathrm{mm} / \mathrm{rev})$. The results therefore confirm those obtained from the Pareto ANOVA and 
Taguchi S/N. It is also worth mentioning that under low cooling level (dry), low cutting speed $(43 \mathrm{~m} / \mathrm{min})$ and high feed rate $(0.33 \mathrm{~mm} / \mathrm{rev})$, the circularity result is close to the optimum combination. Furthermore, Figures 5 and 6 show that the cryogenic cooling method results in the worst circularity performance, while the dry method tends to have the best circularity.

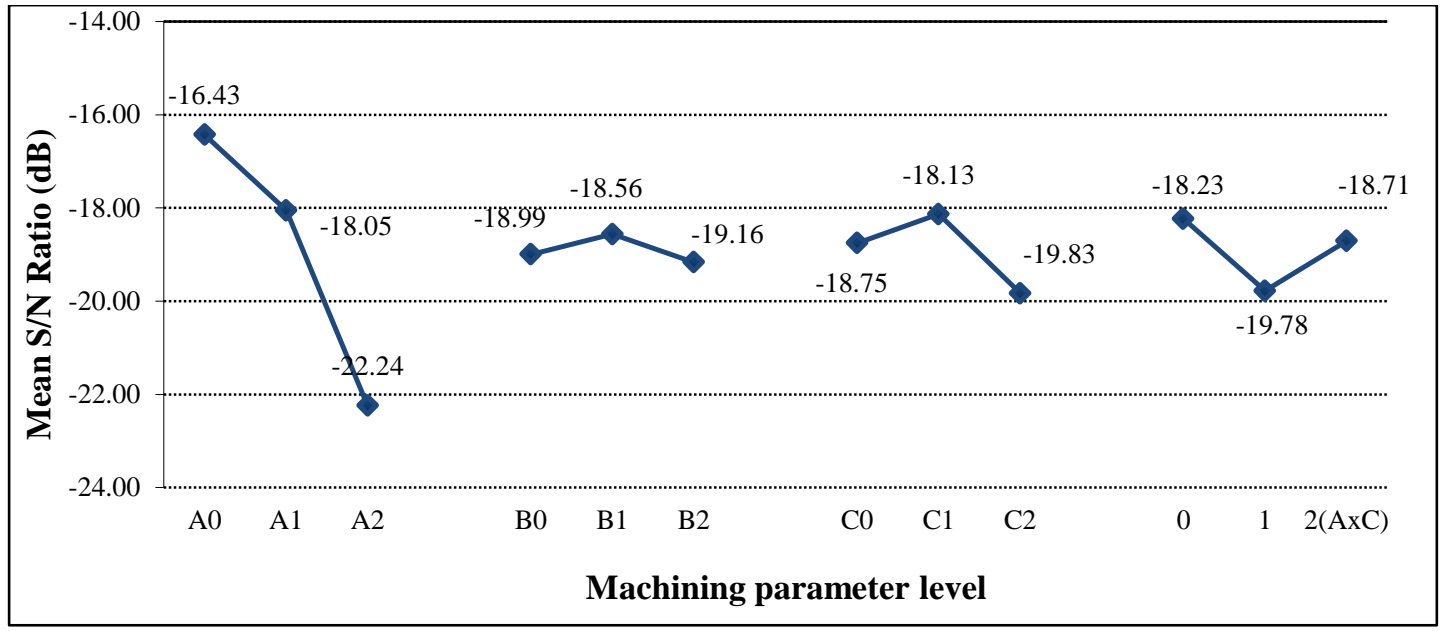

Figure 4 Response graph for mean $\mathrm{S} / \mathrm{N}$ ratio for circularity

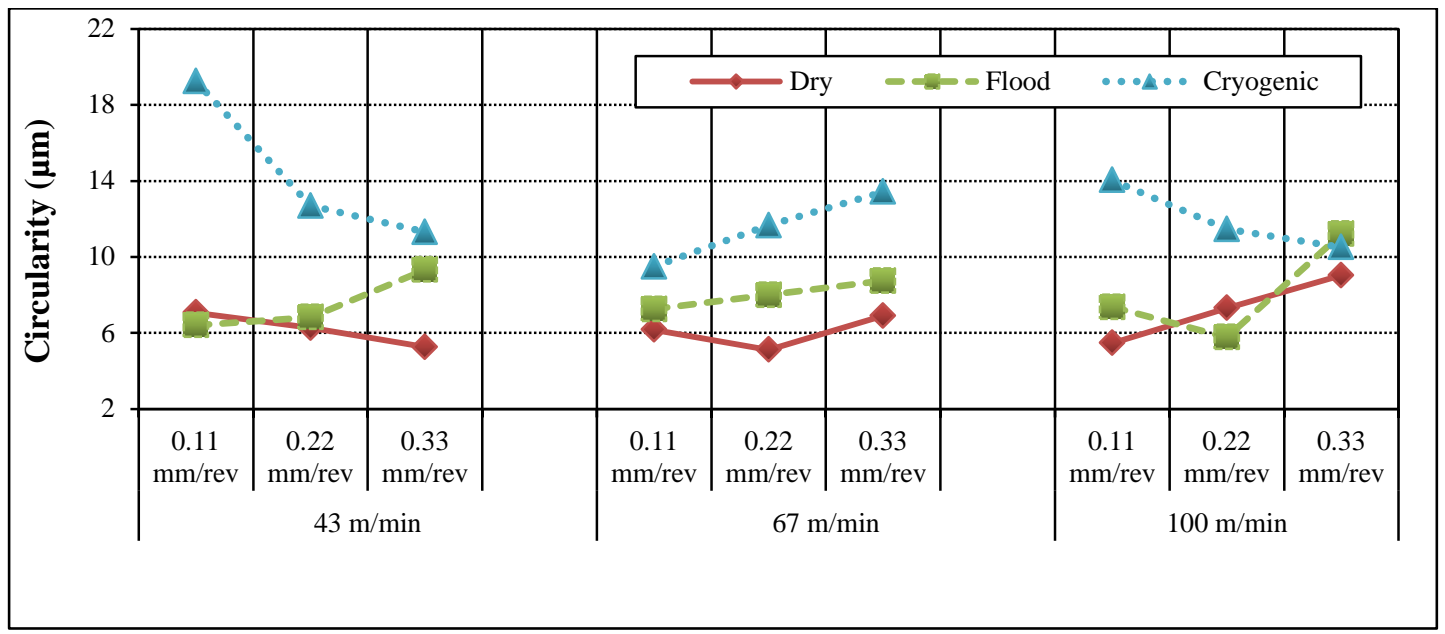

Figure 5 Variation of circularity under three input parameters 


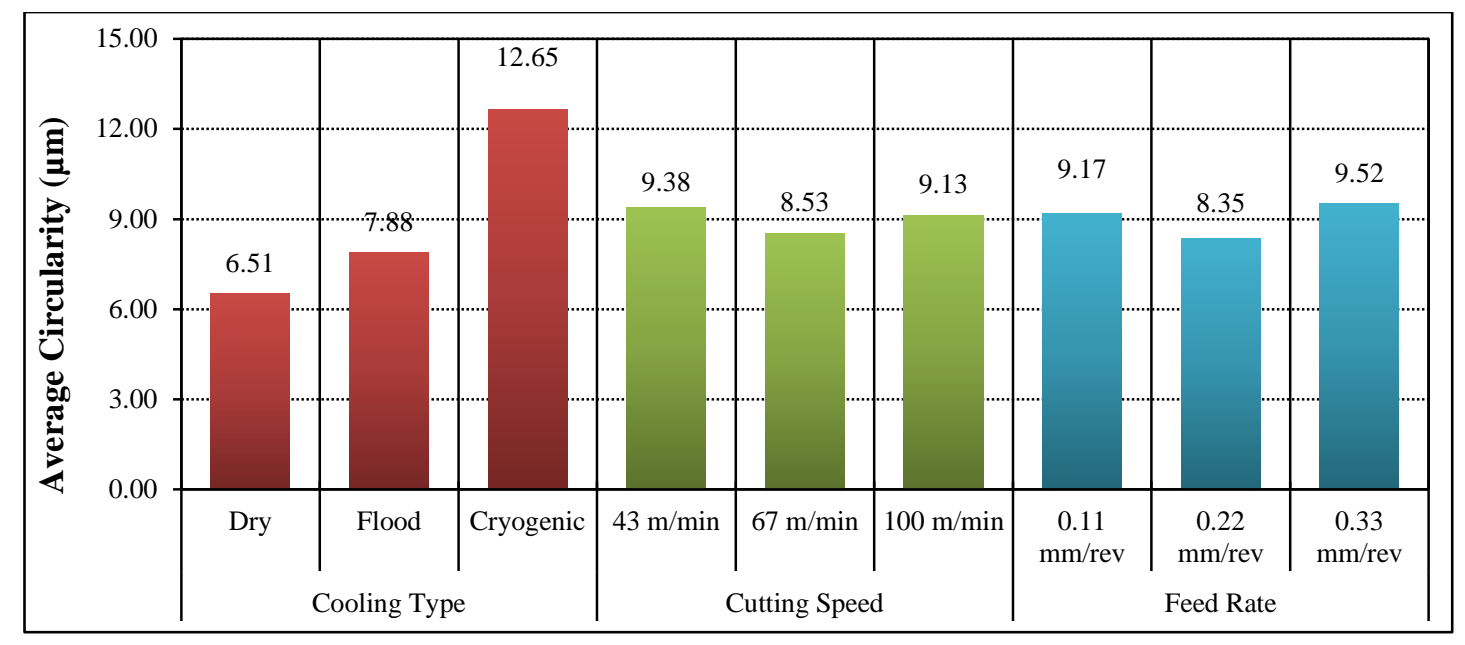

Figure 6 Average variation of circularity under three input parameters

\subsection{Surface Roughness}

The Pareto ANOVA analysis (Table 9) shows that parameter $\mathrm{C}$ (feed rate) has the most significant effect on surface roughness $(\mathrm{P}=97.14 \%)$, followed by A (cooling type, $\mathrm{P}=$ $0.16 \%$ ) and $\mathrm{B}$ (cutting speed, $\mathrm{P}=0.08 \%$ ), which is almost negligible. The $\mathrm{A} \times \mathrm{C}$ interaction (cooling type and feed rate) also plays a role in the cutting process, with $\mathrm{P}=$ 0.96\%. Compared to the interaction effects, the main effects - especially feed ratetend to have the greatest role in achieving optimum results. The total contribution of the main effects is about $97 \%$, compared with $3 \%$ total contribution of the interaction effects, thus making it easier to optimize the surface roughness by selection of input parameters.

The results for mean $\mathrm{S} / \mathrm{N}$ ratio, shown in Table 10 (response table) and Figure 7 (response graph), confirm the Pareto ANOVA finding (Table 9) that parameter C (feed rate) has the most significant effect on surface roughness. 
In selecting the optimum combination of parameters, both the Pareto ANOVA analysis (Table 9) and the response for the mean $\mathrm{S} / \mathrm{N}$ ratio (Table 10 and Figure 7 ) confirm that the medium cutting speed, B1 (value at $67 \mathrm{~m} / \mathrm{min}$ ) achieves the lowest surface roughness. A two-way table was analyzed for the interaction $\mathrm{A} \times \mathrm{C}$, to obtain the optimum levels, indicating that $\mathrm{A} 1 \mathrm{C} 0$ provides the optimum combination of factors to achieve the lowest surface roughness. Thus, the optimum combination to achieve the best circularity is A1B1C0; i.e., medium-level cooling (flood), medium cutting speed $(67 \mathrm{~m} / \mathrm{min})$, and low feed rate $(0.11 \mathrm{~mm} / \mathrm{rev})$.

Further analyses using the traditional methods were conducted as an additional verification of the Pareto ANOVA (Table 9) and Taguchi's S/N (Table 10 and Figure 7). Figure 8 shows a different result, with the lowest surface roughness achieved via the combination of medium cooling type (flood), low cutting speed $(43 \mathrm{~m} / \mathrm{min})$ and low feed rate $(0.11 \mathrm{~mm} / \mathrm{rev})$. As illustrated in Figure 9, the lowest surface roughness is achieved at medium cooling (flood), medium cutting speed $(67 \mathrm{~m} / \mathrm{min})$, and low feed rate $(0.11 \mathrm{~mm} / \mathrm{rev})$. Furthermore, Figure 9 shows that the cooling type and cutting speed had the least effect, compared to the feed rate, on the surface finish of turned titanium parts. 
Table 9 Pareto ANOVA analysis for surface roughness

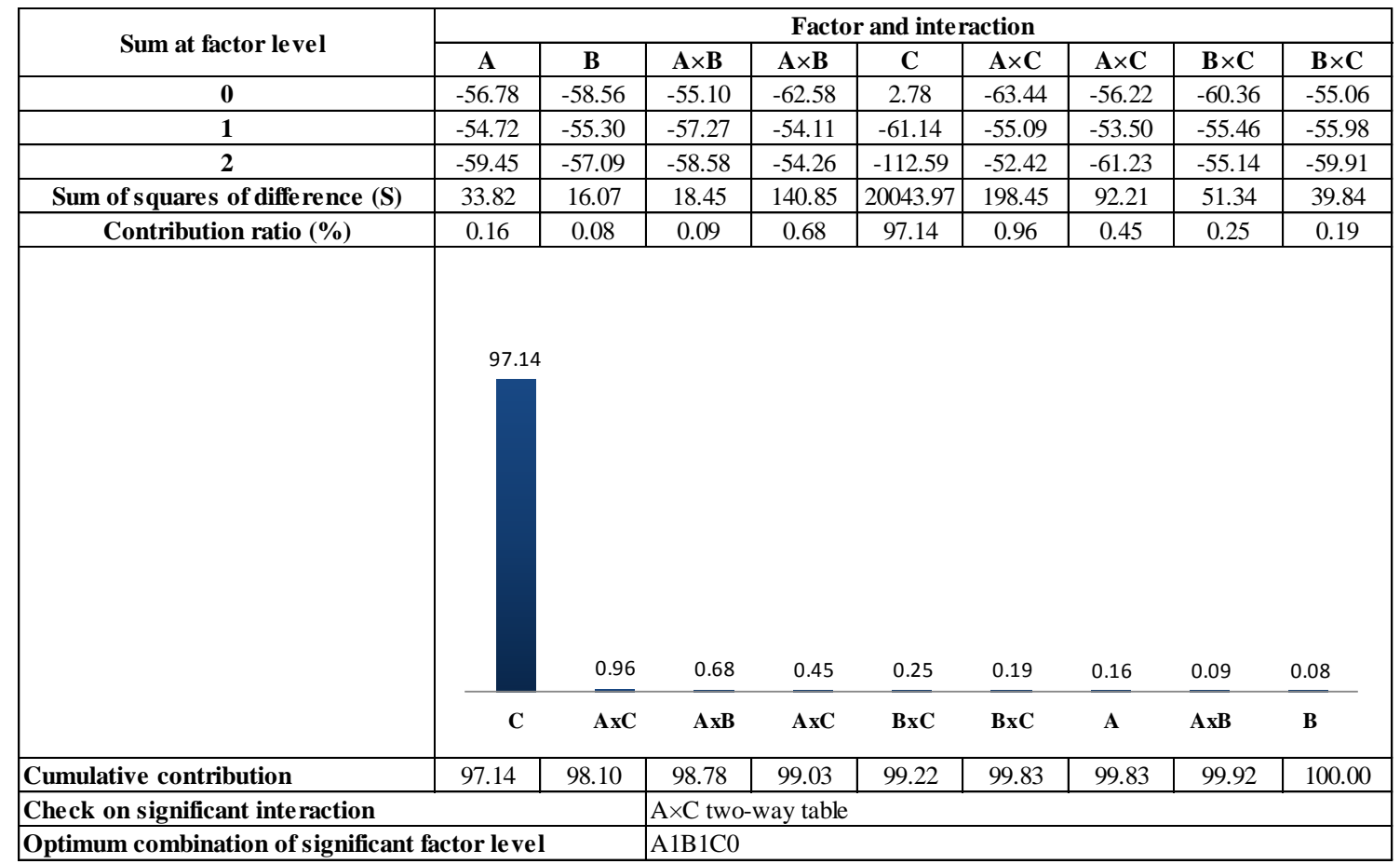

Table 10 Response table for mean $\mathrm{S} / \mathrm{N}$ ratio for surface roughness, and significant interaction

\begin{tabular}{lcrrrr}
\hline & & \multicolumn{4}{c}{ Mean S/N Ratio } \\
\cline { 3 - 6 } Input Parameters & Symbol & Level 0 & Level 1 & Level 2 & Max - Min \\
\hline Cooling Type & $\mathrm{A}$ & -6.31 & -6.08 & -6.61 & 0.53 \\
Cutting Speed & $\mathrm{B}$ & -6.51 & -6.14 & -6.34 & 0.36 \\
Feed Rate & $\mathrm{C}$ & 0.31 & -6.79 & -12.51 & 12.20 \\
Interaction A $\times \mathrm{C}$ & $\mathrm{A} \times \mathrm{C}$ & -7.05 & -6.12 & -5.82 & 1.22 \\
\hline
\end{tabular}




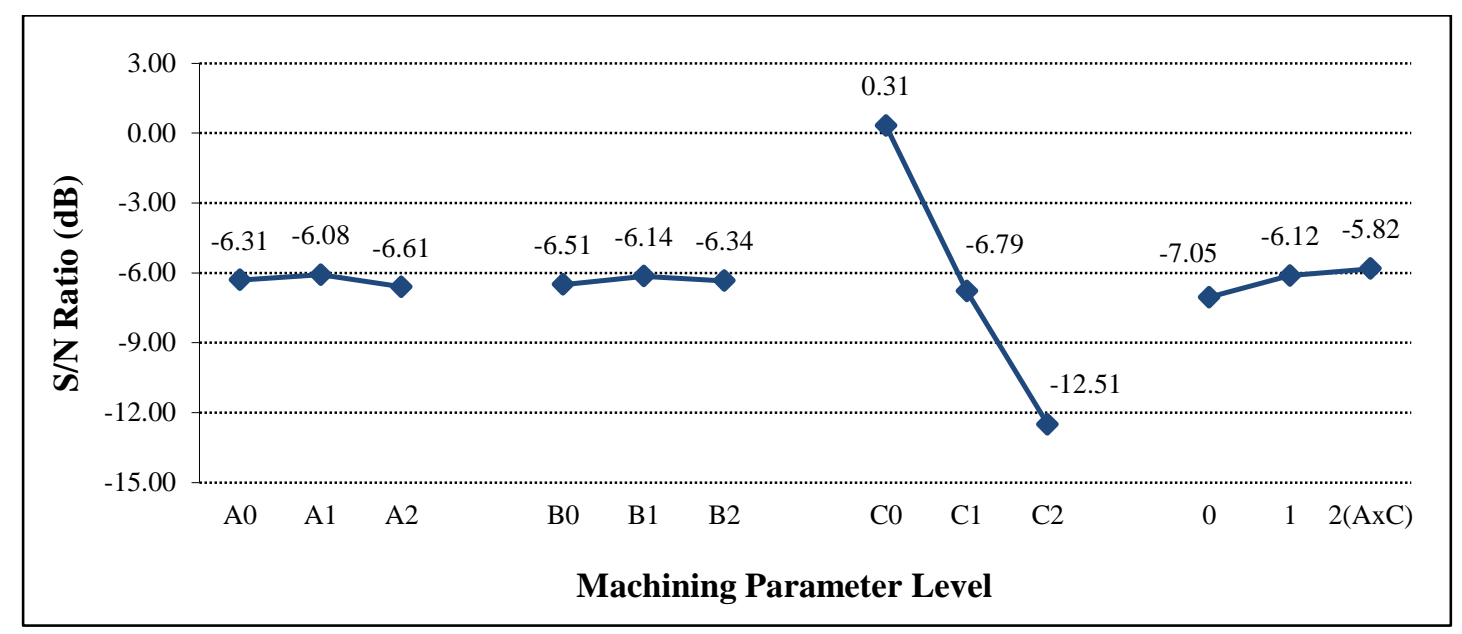

Figure 7 Response graph for mean $\mathrm{S} / \mathrm{N}$ ratio for surface roughness

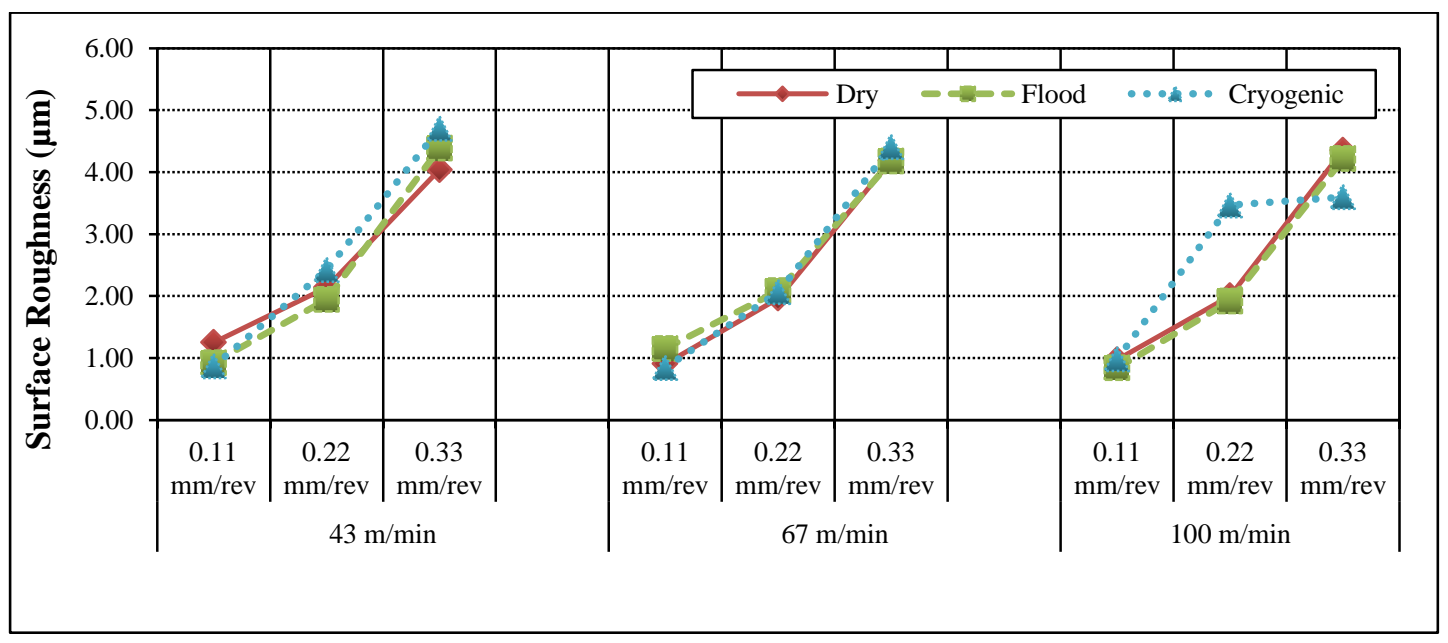

Figure 8 Variation of surface roughness under three input parameters 


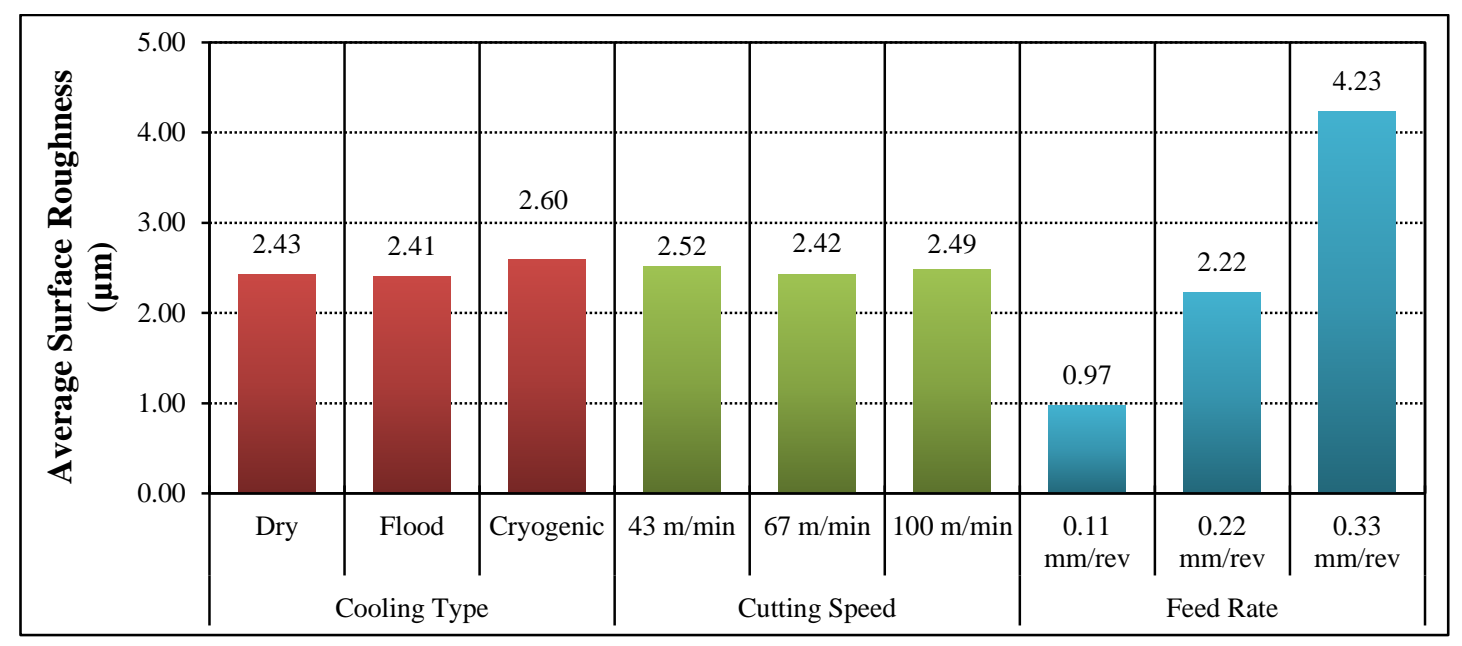

Figure 9 Average variation of surface roughness under three input parameters

\section{Discussion}

The findings indicate that the cooling method has significant effect on circularity error, moderate effect on diameter error and negligible effect on surface finish.

Figure 2 illustrates that cryogenic cooling provided remarkable benefit in minimizing diameter error, especially at high cutting speed $(100 \mathrm{~m} / \mathrm{min})$. This occurs for several reasons, including wear of cutting tool nose, overall compliance of the machinefixture-tool-work (MFTW) system, and the thermal expansion of the workpiece during the machining process. In this study, the MFTW system is rigid due to the three-jaw chuck and the dead-center support. As stated by Dhar et al. [36, 37], diameter error is commonly due to increasing auxiliary flank wear and thermal expansion as the workpiece temperature increases during machining. Thus, in this case, cryogenic cooling had the greatest advantages in reducing temperature, thereby reducing diameter 
error. In addition, cutting speed affects diameter error in a number of ways, such as by changing the elastic deformation of the workpiece induced by: the change in cutting force, tool wear, increasing thermal distortion, formation of a built-up edge (BUE), and increasing radial spindle error [38]. All of these effects were minimized by the use of high-level cooling for the range of cutting speeds considered in the present study.

Table 7 shows that the cooling method has the most significant effect on circularity, and that best circularity is achieved by dry machining (see Figures 5 and 6). Figure 5 shows that the best circularity was achieved at several cutting conditions, such as (i) low cutting speed $(43 \mathrm{~m} / \mathrm{min})$ and high feed rate $(0.33 \mathrm{~mm} / \mathrm{rev})$; (ii) medium cutting speed $(67 \mathrm{~m} / \mathrm{min})$ and medium feed rate $(0.22 \mathrm{~mm} / \mathrm{rev})$; and (iii) high cutting speed (100 $\mathrm{m} / \mathrm{min})$ and low feed rate $(0.11 \mathrm{~mm} / \mathrm{rev})$ with low-level cooling (dry machining) when interactions between all these parameters are considered.

Rafai and Islam [28] attributed the primary cause of circularity error when turning alloy steel AISI 4340 to an overcut of material opposite the position of each jaw of the threejaw chuck, and an undercut of material along the position of each jaw. This is believed to be caused by variation in direction of the radial cutting force with respect to the jaw positions [38]. This is also relevant when machining titanium, as radial stiffness and the stability of the workpiece are significantly influenced by cutting speed and feed rate. Higher feed rate produces forces that accelerate the under/over cut. On the other hand, the machining processes generally become less stable at higher cutting speed. In addition, at lower cutting speeds, the mechanism of titanium failure within the upper region of the primary shear zone appears to be cleavage [10]. It is thought that the adiabatic shear that initiates over the lower region of the primary shear zone does not propagate to the free surface of the titanium workpiece at higher cutting speed. This 
behavior apparently results in ductile fracture. At higher cutting speeds, the correspondingly higher shear strain rates within the primary shear zone favor propagation of the adiabatic shear band further along the shear zone [10]. Shear localization results in a cyclic variation of forces (both cutting and thrust) with a significant variation in magnitude [13]. The consequent vibration or chatter during the cutting process limits the rate of material removal and plays an important role in tool wear. Therefore, circularity, which is generally affected by radial force, is indirectly related to localized softening (due to localized heat generation) and chip formation mechanism [2]. The optimum local softening and chip formation mechanism for best circularity are achieved by the combined effects of feed and cutting speed. In this case, the introduction of flood and cryogenic cooling destabilizes the heating and cooling processes. As shown in Figure 6, circularity gradually increases with greater cooling.

Table 9 shows that cooling method has a negligible effect on surface roughness (contribution ratio $0.08 \%$ ). The same result is found for the interactions between cooling method and other parameters. Feed rate is the only parameter that dominates surface roughness. Surface roughness replicates cutting tool nose. This replication of tool nose is only controlled by the feed rate $[2,39]$. For the same reason, Figures 7 and 8 demonstrate significant influence of feed rate and negligible influence of other parameters on the surface finish. Kumar et al. [40] and Grzesik and Wanat [41] reported similar effect during hard-turning of carbon steels and alloy steels, where surface roughness deteriorated with increased feed rate and cutting time. In the present study, the length of turning is only $20 \mathrm{~mm}$; a longer length of cut may be required to show the effect of cooling method. 


\section{Conclusions}

Based on the results of the present experimental and analytical investigations, the following conclusions can be drawn:

- Cooling method moderately influences diameter error (contribution ratio $25.00 \%$ ). However, cryogenic cooling provides least diameter error when combined with higher cutting speed and medium feed rate.

- Cooling method significantly affects circularity (contribution ratio $76.75 \%$ ). It seems that the cooling method influences the optimum combination of feed rate and cutting speed required for best circularity.

- Dry machining and a combination of feed rate and cutting speed provide optimum circularity due to local softening and chip formation mechanism.

- Cooling method has negligible contribution $(0.16 \%)$ to surface roughness; therefore, feed rate has significant effect on the surface roughness of turned titanium alloy parts.

\section{References}

[1] Kahles JF, Field M, Eylon D, Froes FH (1985) Machining of titanium alloys. Journal of Metals 37: 27.

[2] Pramanik A, Islam MN, Basak A, Littlefair G (2013) Machining and tool wear mechanisms during machining titanium alloys. Advanced Materials Research (accepted).

[3] Zhao H, Barber GC, Zou Q (2002) A study of flank wear in orthogonal cutting with internal cooling. Wear 253: 957-962.

[4] Pramanik A, Zhang LC, Arsecularatne JA (2008) Machining of metal matrix composites: effect of ceramic particles on residual stress, surface roughness and chip formation. International Journal of Machine Tools and Manufacture 48: 1613-1625.

[6] Hong SY, Markus I, Jeong WC (2001) New cooling approach and tool life improvement in cryogenic machining of titanium alloy Ti-6Al-4V. International Journal of Machine Tools \& Manufacture 41 (15): 2245-2260

[7] Wang ZY, Rajurkar KP, Fan J (1996) Turning Ti-6Al-4V with cryogenic cooling. Trans. NAMRI SME 24: 3-8

[8] Kovacevic R, Cherukuthota C, Mazurkiewiez M (1995) High pressure water jet cooling/lubrication to improve machining efficiency in milling. International Journal of Machine Tools \& Manufacture 35 (10): 1459-1473

[9] Ezugwu EO, Wang ZM (1997) Titanium alloys and their machinability - a review. Journal of Materials Processing Technology 68: 262 
[10] Barry J, Byrne G and Lennon D (2001) Observations on chip formation and acoustic emission in machining Ti-6Al-4V alloy. International Journal of Machine Tools and Manufacture 41: 1055

[11] Ahmad JS and Bailey JA (1997) Flow instability in the orthogonal machining of CP titanium. Journal of Manufacturing Science and Engineering-Transactions of the ASME 119(3): 307

[12] Obikawa T, Usui E (1996) Computational machining of titanium alloy-finite element modelling and a few results. Journal of Manufacturing Science and Engineering-Transactions of the ASME 118: 208.

[13] Komanduri R, Hou ZB (2002) On the thermoplastic shear instability in the machining of a titanium alloy (Ti-6Al-4V). Metallurgical and Materials Transactions 33A: 2995.

[14] Jawaid A, Haron CHC, Abdullah A (1999) Tool wear characteristics in turning of titanium alloy Ti-6246. Journal of Material Processing Technology 92-93: 329.

[15] Jianxin D, Yousheng L, Wenlong S (2008) Diffusion wear in dry cutting of Ti-6Al-4V with WC/Co carbide tools. Wear 265: 1776

[16] Konig W, Fritsch R, Kammermeier D (1991) Physically vapour deposited coatings on tools: performance and wear phenomena. Surface Coatings Technology 49: 316.

[17] Molinari MN (2002) Modeling of tool wear by diffusion in metal cutting. Wear 252: 135.

[18] Jawaid A, Sharif S, Koksal S (2000) Evaluation of wear mechanisms of coated carbide tools when face milling titanium alloy. Journal of Materials Processing Technology 99: 266

[19] Su Y, He N, Li L, Li XL (2006) An experimental investigation of effects of cooling/ lubrication conditions on tool wear in high-speed end milling of Ti-6Al-4V. Wear 261 (7-8): 760-766.

[20] Dearnly PA, Grearson AN (1986) Evaluation of principal wear mechanisms of cemented carbides and ceramics used for machining titanium alloy IMI 318. Material Science and Technology 2: 4758

[21] Davim JP (2001) A note on the determination of optimal cutting conditions for surface finish obtained in turning using design of experiments. Journal of Materials Processing Technology 116: 305-308

[22] Marcos-Bárcena M, Sebastián-Pérez MA, Contreras-Samper JP, Sánchez-Carrilero M, SánchezLópez M, Sánchez-Sola JM (2005) Study of roundness on cylindrical bars turned of aluminiumcopper alloys UNS A92024. Journal of Materials Processing Technology 162-163: 644-648

[23] Tzeng CJ, Lin YH, Yang YR, Jeng MC (2009) Optimization of turning operations with multiple performance characteristics using the Taguchi method and Grey relational analysis. Journal of Materials Processing Technology 209: 2753-2759

[24] Lalwani DI, Mehta NK, Jain PK (2008) Experimental investigations of cutting parameters influence on cutting forces and surface roughness in finish hard turning of MDN250 steel. Journal of Materials Processing Technology 206: 167-179

[25] Manna A, Bhattacharyya B (2002) A study on different tooling system during machining of Al/SiC-MMC. Journal of Materials Processing Technology 123: 476-481

[26] Thamizhmanii S, Saparudin S, Hasan S (2007) Analyses of surface roughness by turning process using Taguchi method. Journal of Achievements in Materials and Manufacturing Engineering 20: 503-506

[27] Nalbant M, Gokkaya H, Sur G (2007) Application of Taguchi method in the optmization of cutting parameters for surface roughness in turning. Materials and Design 28:1379-1385

[28] Rafi NH, Islam MN (2009) An investigation into dimensional accuracy and surface finish achievable in dry turning. Machining Science and Technology 13: 571-589

[29] Sharma VS, Dogra M, Suri NM (2009) Cooling techniques for improved productivity in turning. International Journal of Machine Tools \& Manufacture 49: 435-453

[30] ASME, 2009. ASME Y14.5-2009, Dimensioning and Tolerancing, ASME, New York

[31] Australian Standard, 1982. AS 2536-1982, Surface Texture, Standards Australia, Sydney

[32] Park SH (1996) Robust Design and Analysis for Quality Engineering, Chapman \& Hall, London

[33] Ross PJ (1988) Taguchi Techniques for Quality Engineering, McGraw-Hill, New York

[34] MatWeb, Material Property Data, http://www.matweb.com/ Accessed 10 January 2013

[35] Taguchi G (1987) System of Experimental Design: Engineering Methods to Optimize Quality and Minimize Costs. Ed. Don Clausing 1987: 2. UNIPUB/Kraus International Publications, White Plains, NY

[36] Dhar NR, Islam MW, Islam S, Mithu MAH (2006) The influence of minimum quality lubrication (MQL) on cutting temperature, chip and dimensional accuracy in turning AISI-1040 steel. Journal of Materials Processing Technology 171: 93-99 
[37] Dhar NR, Kamruzzaman M, Ahmed M (2006) Effect of minimum quantity lubrication (MQL) on tool wear and surface roughness in turning AISI-4340 steel. Journal of Materials Processing Technology 172: 299-304

[38] Islam MN (2013) Effect of additional factors on dimensional accuracy and surface finish of turned parts. Machining Science and Technology: An International Journal (in press)

[39] Pramanik A, Neo KS, Rahman M, Li XP, Sawa M, Maeda Y (2003) Cutting performance of diamond tools during ultra-precision turning of electroless-nickel plated die materials. Journal of Materials Processing Technology 140(1): 308-313

[40] Kumar NS, Shetty A, Ananth K, Shetty H (2012) Effect of spindle speed and feed rate on surface roughness of Carbon Steels in CNC turning. International Conference on Modelling, Optimization and Computing (ICMOC) 38: 691-697

[41] Grzesik W, Wanat T (2006) Surface finish generated in hard turning of quenched alloy steel parts using conventional and wiper ceramic inserts. International Journal of Machine Tools \& Manufacture 46: 1988-1995 